Article

\title{
A Framework for Cloud Based E-Government from the Perspective of Developing Countries
}

\author{
Pusp Raj Joshi, Shareeful Islam * and Syed Islam \\ School of Architecture, Computing and Engineering, University of East London, London E162RD, UK; \\ u1344224@uel.ac.uk (P.R.J.); syed.islam@uel.ac.uk (S.I.) \\ * Correspondence: shareeful@uel.ac.uk; Tel.: +44-2082237273
}

Received: 17 August 2017; Accepted: 2 November 2017; Published: 9 November 2017

\begin{abstract}
Despite significant efforts to initiate electronic government projects, developing countries are still struggling to reap the benefits of using e-government services. An effective implementation of e-government infrastructure is necessary to increase the efficiency and transparency of the government services. There are several studies that observed causes like lack of infrastructure support, lack of payment gateway and improper e-government service delivery channel as main barriers to a wider adoption of e-government services. The main contribution of this research is to propose a cloud-based G2G (Government-to-government) e-government framework for a viable e-government solution from the perspective of developing countries. We have introduced a list of concepts and a systematic process to guide the implementation of e-government project based on the government's vision, goals, chosen services through the service delivery channel to the appropriate cloud service and deployment model. We have used Nepal as a context of the case study and applied the framework to a real e-government project of driving licensing department using action research methodology. The results from the study show that the G2G approach of e-government implementation would be the best for providing effective government services to the stakeholders of developing countries. The proposed framework also supports a smooth integration of government services and reduces the time of the overall project.
\end{abstract}

Keywords: cloud computing; e-government; government-to-government; vision; risk; citizen-centric approach

\section{Introduction}

The phenomenon of e-government in the past couple of decade has taken the government service delivery approach to the next level. The advancement in technology has brought such a dramatic change that almost every government service could be delivered and acquired electronically in the developed countries [1]. This trend has attracted many developing and less developed countries to implement e-government solutions in order to enhance the government service delivery approach that would save government resources. However, e-government projects in developing countries suffer a poor success rate in that only 30 percent of e-government projects manage to sustain the actual delivery stage [2]. Al-Hujran et al. [3] found that e-government users in developing countries have minimal access to the ICT tools that ultimately restricts access to the offered e-government services. Among the various reasons for e-government failure, the lack of adequate ICT infrastructure, payment gateway and e-government service delivery channels are some of the major issues [4]. Beside this, the lack of attention to e-government adoption while designing and implementing e-government projects is one of the major contributors to e-government project failure. Lessa et al. [5] found that governments put a high emphasis on the sophistication of the technology for e-government implementation while the adoption part is often overlooked, creating a gap in the implemented service and user strength to adopt those services. Therefore, merely having an online portal and offering 
government services through this portal is not enough to gain citizen participation [6]. Symasuddin [7] found that the government approach for initiating an e-government in the government-to-citizen (G2C) dimension is problematic for developing countries especially when e-government systems are not integrated. Farzali et al. [8] also identified that the lack of integrated e-government systems makes the offered services incomplete and discourages users from getting involved. In the context of aforementioned scenario, it is imperative to develop a viable e-government implementation solution that supports governments to effectively implement and integrate existing e-government systems to better align them with citizens need.

The novel contribution of this paper is a framework that: (i) supports a cloud-based government-to-government (G2G) e-government solution that would provide a strategic roadmap for successful e-government implementation from the perspective of developing countries; and (ii) includes several concepts and a systematic process that are necessary for e-government implementation and justifies different service delivery channels and transaction processing models to deliver e-government services through a more citizen-centric approach. The proposed framework has been validated for its usability and adoptability in the context of developing countries and the impact it would bring in the government service delivery. The framework further supports to identify various e-government service delivery channels and payment processing models for the citizen-centric services. We have adopted participatory action research in order to evaluate the framework and the findings show its positive impact in line with the aim and objective of this paper.

\section{Related Works}

Information communication technology driven projects often need to be aligned with innovations and new technologies [9] and the changing nature of technology results in the constant upgrade and update of the electronic government infrastructure, creating an extra financial burden for governments [10]. Similarly, when a government extends its department or makes any change in governance, it needs to modify or build a new infrastructure to accommodate those changes [11] that demand significant amount government resources. Therefore, governments throughout the world are developing strategies to migrate to cloud based e-government to reduce spending on technology infrastructure [12]. Besides the cost factors, upgrading the conventional e-government system requires a significant amount of time-Microsoft UK government industry manager, Richard Shipton says, "Traditionally you might be looking at a six month or a year's project to buy and install extra storage. Now you can do it just by going to a web page and using your government procurement card." According to Gartner Inc. (Stamford, CT, USA) [13]—the world's leading information technology research and advisory company - by 2018, at least 30 percent of service-centric companies will have moved the majority of their Enterprise Resource Planning applications to the cloud in order to address the growing financial challenges requiring the cutting of the costs of ICT infrastructure.

Zhang and Chen [14] have discussed the impact of shrinking budget in e-government projects and government initiatives to shift from traditional to cloud based e-government. While electronic government projects are facing a number of challenges [15], cloud computing is considered as a future solution for addressing those challenges. Cloud computing has opened new channels in which governments can deploy electronic government projects and creates new business opportunities while improving performance and cost reduction efficiently for both business and government [16,17]. Smitha et al. [16] suggest that the integration of the cloud computing in e-government could solve a number of problems including data duplication, low resource utilization rate, repetitive infrastructure construction and information isolated island. Besides this, governments could be benefited from overall cost reduction, distributed data storage, scalability, accountability, modifiability and security management by using cloud computing [9,18-21].

Traditional e-governments are not scalable and cost a lot to change their capacity [22]. A typical example of the traditional e-government system failure because of the lack of scalability is Transport for London's (TFL) real-time train tracking system failure in 2010. The app became so popular that 
the TFL's servers struggled to cope with the sudden increase in demand. To address the problem TFL moved the application from its server to the Microsoft Azure Cloud infrastructure. The current system is comfortably handling about 2.3 million hits it receives each day. Michael Gilbert, transport of London (TfL)'s chief technology officer accepts that if they had to run the application on their own servers it would have financially prohibiting as it would have cost them a huge amount to build a new infrastructure inside their data centres.

\section{Cloud Based E-Government Framework}

The proposed cloud based G2G e-government framework has been designed to address the challenges faced by e-government projects in developing countries. As discussed in the literature review, the huge number e-government projects failure has motivated us to develop this framework that would support governments to successfully implement and manage e-government projects. The framework consists of a list of concepts and processes necessary to execute those concepts. The concepts are interrelated to support the initialization of e-government project by defining the vision, handling the execution strategy and monitoring the results.

Vision: Government vision is a core concept of the proposed framework. Generally, the vision for the electronic government is directed towards the betterment of e-government services and to accumulate wider public acceptance. The consequences aroused from the problem domain motivate governments to draw a vision. The vision for the cloud based G2G electronic government framework is to integrate e-government systems to deliver seamless government service to the stakeholders via various delivery channels as required.

Goals: Government vision to achieve successful electronic government are further refined through the goals. We consider two different types of goals.

\section{- $\quad$ Technological Goal:}

The technological goals are associated with the electronic government readiness. It defines the government intention to enhance or upgrade the existing information communication technology infrastructure by adopting appropriate model. Therefore, the technological goal for adopting the cloud based e-government framework is to achieve infrastructural support and the integrated e-government system.

\section{- Organisational Goal:}

The success of e-government projects is highly influenced by its acceptance and adoption ratio. The organisational goals focus on the adoption and acceptance of the e-government services by the stakeholders. The organisational goal of the cloud based G2G electronic government framework is to support government to better align its online service with the stakeholder's need, by defining range of delivery channels.

Approach: The concept approach defines the different dimensions of e-government stakeholders and their relationship. E-government project implementation occurs mainly in three dimensions-government-to-government (G2G), government-to-citizen (G2C) and government-to-business (G2B). In the context of the proposed framework government-to-government (G2G) approach has been considered most appropriate for developing countries.

Strategies: Strategies operationalise the goals for its implementation. Based on the selected approach and defined goals, the strategies can be technological and organisational dimensions. A strategy for technological dimension supports the framework approach by identifying the e-government readiness and required information communication technology infrastructure. Similarly, organisational dimension deals with the organisational readiness for the framework that assesses the strength and limitation of the government departments or a government as a whole to accept the change.

E-government model: The concept e-government maturity model provides detailed e-government implementation plan. Once the goals are set, approaches are defined and the strategies are developed, an implementation model is generated to initiate e-government projects. The model 
defines the different stages and the activities under those stages required for e-government assimilation process. The concept uses predefined strategies to assess and evaluate the implementation and integration platform along with the appropriate e-government adoption model.

Risks: Risk is a potential consequence which can negatively impact on the overall electronic government implementation. Along with the opportunities, migration of the electronic government to the cloud brings many challenges. A critical challenge in many existing information systems while migrating to the cloud computing platform is lack of detailed documentation on information system architecture and functionality specifications. Governments need to adopt an appropriate strategy to identify, manage and mitigate the risk. However, all the potential risks are difficult to identify, therefore a contingency risk management plan should be in place to manage and minimize the risks occurred during and after the framework implementation [23].

E-government services: The concept identifies the government services required to migrate to the cloud computing platform. E-government services need to be identified, categorized and prioritized based on their workload and criticality allowing the selection of appropriate deployment platform. E-government services use adoption model defined by e-government maturity model to acquire maximum potential participation from the user. Finally, the implemented e-government services are mapped to the framework goal to evaluate their alignment with the government vision.

\subsection{Cloud Based G2G Conceptual Model}

The conceptual model integrates the concepts used for the cloud based G2G e-government framework. The concepts are linked together to support from identification of vision for the e-government project to implementation. The key concepts may be divided into further sub-concepts at the different stages of the cloud based G2G framework assimilation. Vision remains at the centre of the concepts that encourages the government to set goals for citizen-centric e-government services. The defined goals are then categorized as organizational and technological. The categorization of the goals guides government in developing appropriate strategies to achieve each goal while providing a roadmap to select an e-government approach. The aim of the cloud based G2G e-government framework is to achieve citizen-centric e-government service, therefore two concept delivery channel and transaction mode have been added to support the adoption model. The concept risk defines the potential risk associated with the implementation and integration platform that influence the e-government user decision to adopt e-government services and may pose threat to the framework goal. E-government services are supported by the implementation platform and integration platform in an attempt to meet the goal and support the government vision. Figure 1 depicts the concepts used to develop the framework and the relationships among those concepts.

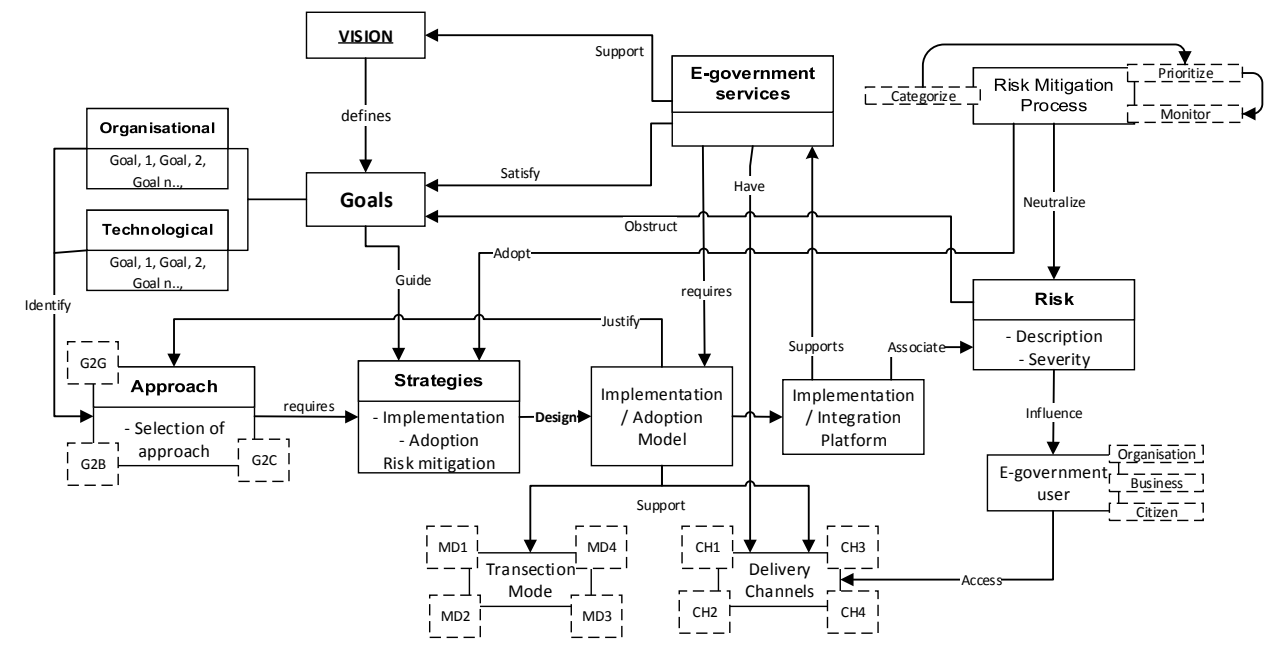

Figure 1. Cloud based G2G conceptual model. 


\subsection{Cloud Based G2G E-Government Framework Stages and Assimilation Process}

The cloud based G2G e-government framework supports the government to assimilate e-government project in four different stages which provides the detailed process and strategies to rollout, implement and evaluate the cloud based e-government systems. The stages are arranged in a linear sequence, that each stage produces an output for the next stage. The stages and activities under these stages are discussed in this section and shown in Figure 2.

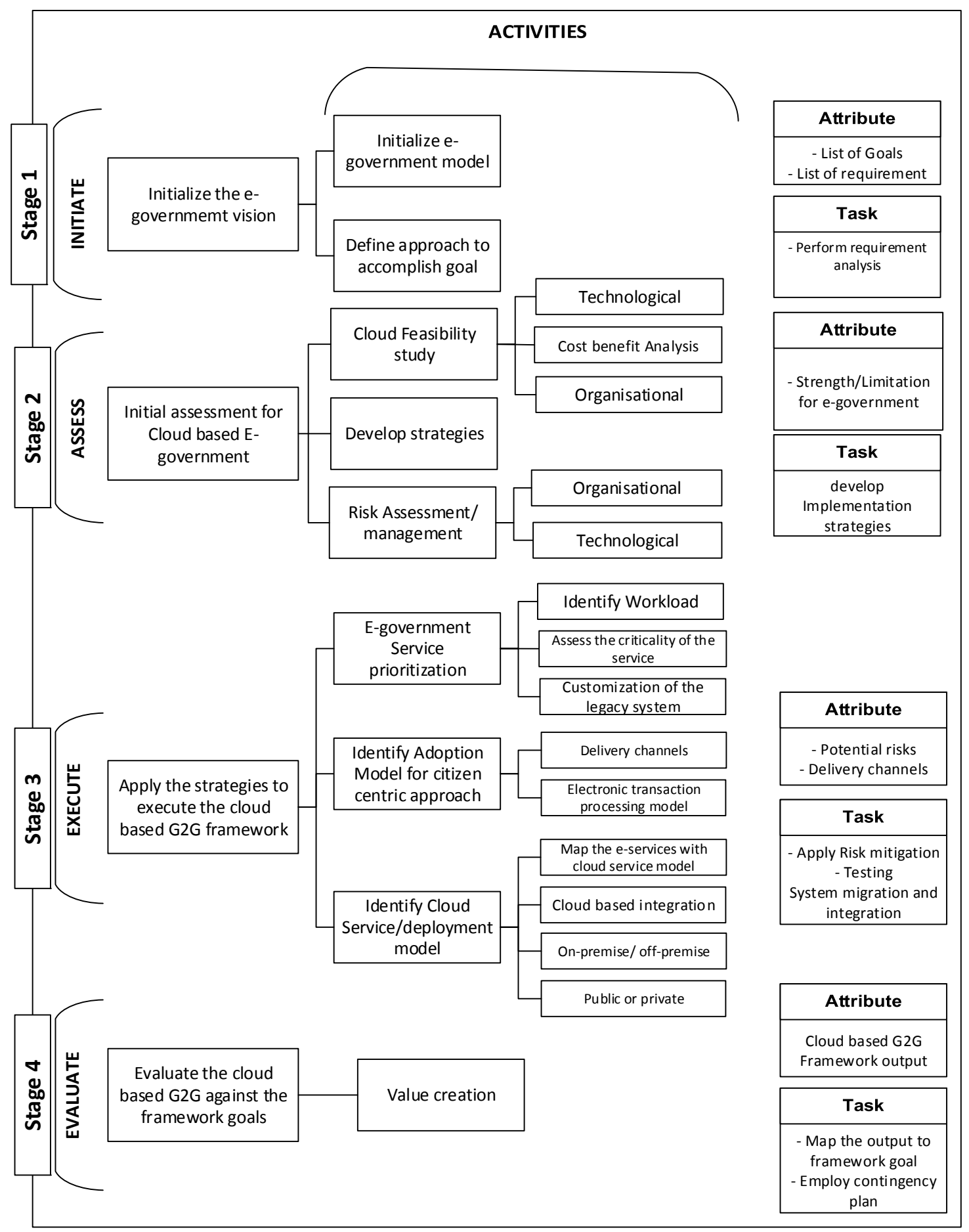

Figure 2. Cloud-based G2G e-government framework stages and assimilation process. 
Stage 1: Initiate: This is the initial stage of the cloud based G2G government implementation. The activities under this stage justify the need for the cloud based electronic government to realize the government's vision. The vision to achieve citizen-centric e-government services drives governments to identify the possible solutions for the problem faced by e-government projects. The main contribution of this stage is to apply government vision to identify the problems, set goals to address those problems and to perform requirement analysis to accomplish e-government goals. The following activities are performed at this stage.

Activity 1: initialize the government maturity model

The initial activity under the stage is to initialize e-government maturity model. E-government projects require a detailed plan and assimilation framework to develop and implement. E-government maturity model would guide the government through the cloud based e-government assimilation process. The maturity model defines the essence of the cloud platform for the proposed e-government. Once the maturity model has been adopted the government needs to map the level of current e-government practice with the maturity level of the model. That will support the project initiator to decide where to start from. The cloud based G2G government framework has been proposed considering e-government maturity level in the particular country is at least at the first stage. The government needs to meet certain requirements to complete each stage.

Activity 2: Defining approach to accomplish goal

Once the goals are defined, an e-government implementation approach needs to be identified. The electronic government approach could be defined as a way that the government connects with the different stakeholders such as citizen, business, end users, organization and other government departments. The framework adopts government-to-government (G2G) e-government approach to support governments for better service delivery. Government-to-government $(G 2 G)$ is the electronic sharing of data and/or information systems between government agencies, departments or organizations.

While G2G initiatives are usually not apparent to the general public, it allows more coordinated inter-governmental connection because of improved information access and greater service efficiency for the customers. Developing G2G applications as a way to deliver G2C or G2B services is necessary when two or more government entities need to cooperate or share information to complete a particular transaction for citizens or businesses. In order to process an online service request from businesses or citizens, two or more government entities need to connect their business processes to allow multiple databases to interact. Integration of the government departments for the seamless data and information exchange is essential for successful electronic government system. Integration allows government departments to access the shared pool of data and information that allows government departments to deliver the services to the stakeholders in more efficient and effective manner. Once the governmental entities can interact with each other they can offer citizens or businesses consolidated service.

Activity 3: Perform requirement analysis

At this stage, a requirement analysis needs to be performed to summarize the identified requirements from the different users. The term user is used for both government and its stakeholders. The government might have different requirements in relation to the implementation of the framework i.e., cost, expertise, risk involved, cost-benefit etc. Meanwhile, the stakeholders might have requirements in relation to the effectiveness of the services, accessibility of the services through different channels, reliability and authenticity of the online service and privacy and security assurance. Interview and government report should be used to extract government requirements. These requirements should be than categorized and explained to identify which of these are to be addressed by the proposed framework. 
Stage 2: Assess: This is the second stage of the cloud based G2G e-government framework. Assessment involves complex activities as it deals with both technical and non-technical aspects of the process. The objective of the activities performed under this stage is to assess e-government readiness of a particular government to find whether it has sufficient resources to implement e-government project. The following activities are performed under this stage.

Activity 1: Perform cloud feasibility study

A feasibility study is required to assess the technical and organizational readiness of the government in order to adopt the cloud based e-government. After the feasibility study a report will be produced that would show the strength and weakness of the government. The feasibility study will be conducted under three dimensions; technical, financial and organizational.

- Technical feasibility: Technical feasibility supports the government to identify the technological strength and weakness of the government for adopting cloud based e-government.

- Financial feasibility: Financial feasibility supports to make decision, whether the proposed system, is financially feasible for adoption or not. Cost benefit analysis is performed under this activity. Cost benefits analyses compares and weigh the benefits and cost of the framework in order to determine its feasibility, usability and adoptability of the framework as shown in Figure 3. The activity decides whether the framework is performing well in the different dimension and meeting the government expectation. Cost benefit analysis determines whether employing cloud based G2G framework is justified in terms of the financial benefit or savings. It compares the information communication technology infrastructure establishment cost with the cost involved using cloud platform for deploying electronic government projects. Having said that, cost benefit analysis is not always discussed in the context of monetary value gain. Therefore, the cloud based framework evaluates the benefits of the cloud based G2G e-government framework against its cost.

- Organizational feasibility: organizational feasibility supports the government to decide whether the organizational structure is ready to accept the new change. It would further support the government to make an appropriate strategy to manage the change in the organization.

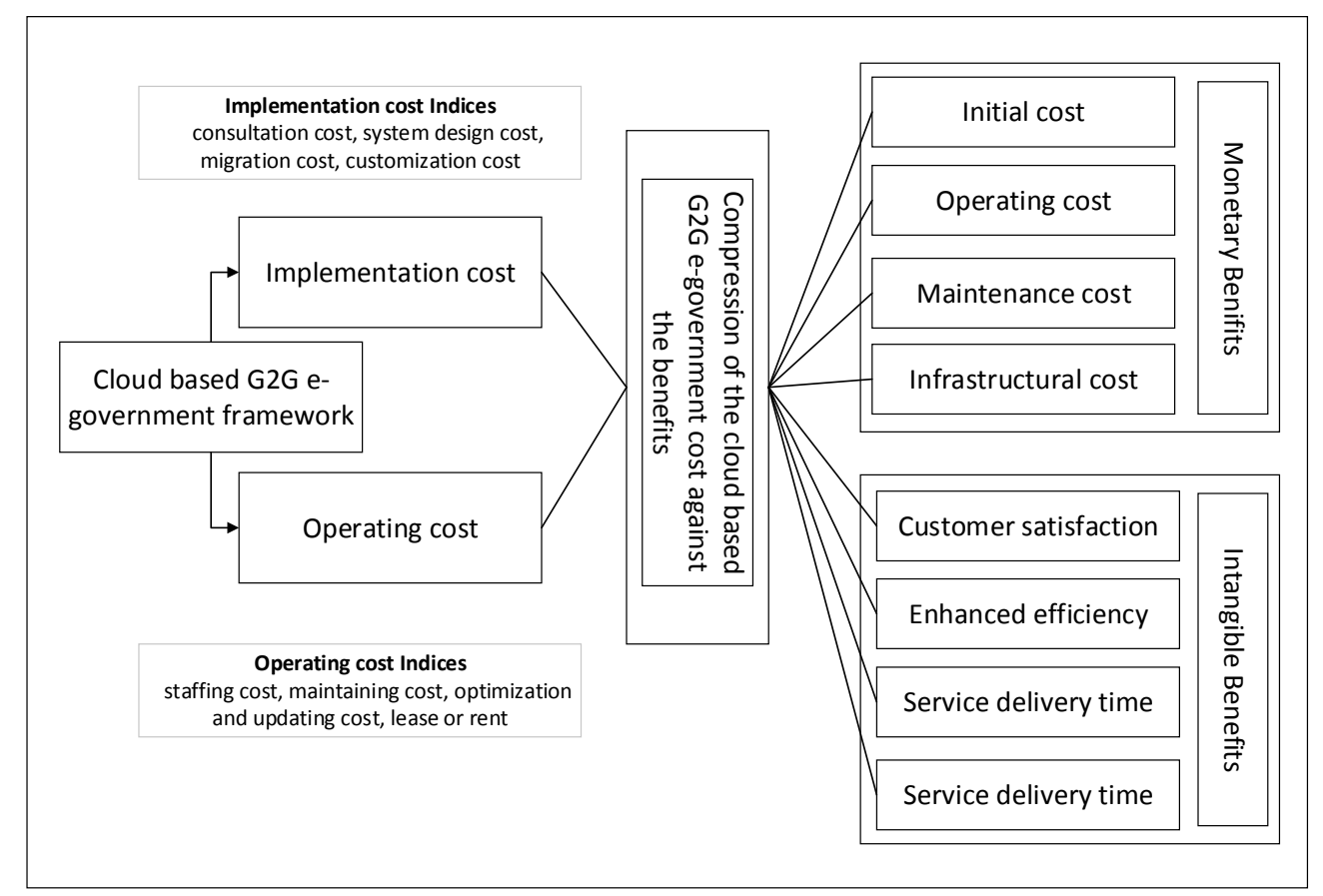

Figure 3. Cost benefit analysis. 
Activity 2: Develop strategies

Strategy is a systematic plan of action developed to achieve a goal. There are many short- and long- term strategies required in order to achieve the successful electronic government implementation. Cloud based G2G e-government framework requires multi-dimensional strategies, those can be categorized as technological, organizational and cloud computing.

i. Technological strategies

The framework support to develop appropriate technological strategies in order to implement cloud based G2G e-government. A technological strategy covers all the technical aspect that are required to migrate the existing system to the cloud or implement a new system in cloud. The framework support government to develop following strategies.
- $\quad$ ICT infrastructure development
- $\quad$ E-government interoperability framework
- $\quad$ E-government services prioritization
- $\quad$ E-government delivery channels
- $\quad$ Electronic transaction

\section{ii. Organizational strategies}

Organizational strategies ensure the organizational readiness for smooth migration of the existing electronic government service to cloud based electronic government. The framework supports the development of the following organizational strategies those are required to adopt the cloud based e-government.

$$
\begin{array}{ll}
\text { - } & \text { Government policies } \\
\text { - } & \text { Change management } \\
\text { - } & \text { Data sharing (G2G) } \\
\hline & \text { Knowledge management }
\end{array}
$$

iii. Cloud computing strategies

This includes the selection of the cloud service, cloud deployment model and the government cloud readiness to migrate its applications. The cloud computing strategies covers the following area.

- Cloud readiness of existing e-government application: Cloud readiness refers to the strength of the existing application and system to perform in the cloud computing environment. Based on the existing government applications and systems, the governments need to make an appropriate strategy to make them cloud computing compatible. It is worth spending some time and resources to assess the cloud readiness of the existing system before the government make cloud migration decision. Several factors need to be considered while assessing e-government application for their cloud readiness. Dependencies of the existing e-government system and application, the system and application architecture and the workload are the key parameters to assess the cloud readiness of an e-government. Table 1 summarizes the attributes for cloud readiness of an existing e-government application or a system. Individual applications are assessed against the given attributes and outcome is recorded as ready, partially ready or not ready. The attributes mainly assess the inter application dependencies, complexity and workload or traffic that can be handled.

- Cloud service model/Cloud deployment model: Once the application and systems are ready to deploy in the cloud platform, the government needs to make appropriate 
strategies to adopt cloud services and deployment mode. Since the government uses their own customized applications and those applications run on the particular environment, infrastructure as a service model is required. Some of the government application, i.e., email, or some collaborative application software i.e., word processing could be taken as software as a service. The deployment model depends on the availability of the budget and time. If the government have enough budget and time, then they should go for a secure private cloud, however this may not be feasible for developing countries.

Table 1. Cloud readiness assessment.

\begin{tabular}{lcccc}
\hline Application/System & $\begin{array}{c}\text { Workload } \\
\text { (High/Low) }\end{array}$ & $\begin{array}{c}\text { Application } \\
\text { Architecture }\end{array}$ & $\begin{array}{c}\text { Dependencies } \\
\text { (Y/N) }\end{array}$ & $\begin{array}{c}\text { Summary (Ready/Not } \\
\text { Ready/Partially Ready) }\end{array}$ \\
\hline
\end{tabular}

Activity 3: Risk assessment and management

This activity aims to identify the potential risks that could obstruct the government vision to achieve for e-government project so that suitable control can implemented from the early stage. It consists of two steps, risk identification, analysis and control.

Risk identification: This step identifies and categorizes all the possible risks that could have an impact on the cloud based e-government project. We need to follow existing techniques such as checklist, government/e-government services, cloud based system context, interviewing the employees and user to identify the risks. Once the risks are identified they are categorized into three types:

- Business risks: Such risks can directly oppose the government vision and incur financial loss for the government. It is directly linked with the financial feasibility.

- Organization risks: These risks focus on existing government departments' organizational structure and their suitability for the new cloud based system. It also focuses on the user perspective.

- Technical risks: These risks consider the technical issues for an existing application and their migration into the cloud. Furthermore, technical risks also consider the threats relating to security and privacy as they are one of the main concerns for migration to the cloud.

Risk analysis and control: Once the risks are identified next step is to determine the severity of the risks so that appropriate control actions can be identified. The risk level is determined based on the probability of the risks and its impact. i.e., $R=P(R) \times I(R)$, where, $P(R)$ is the probability and $I(R)$ is the impact of risk $R$. We consider three different risk levels. They are: low risks (less than 0.3), high risk (between 0.3-0.60) and critical risk (more than 0.60). Depending on the severity of the risk we need to choose appropriate risk control strategies such as reduction, prevention, retain and transfer. At this early stage, it is recommended to prevent or reduce all identified highly critical risks for a successful e-government project.

Stage 3: Execute: This is the most critical stage of the cloud based G2G framework where the government implements the strategies to migrate the electronic government system to the cloud computing platform. The execution strategies are developed based on the attributes acquired from the initial assessment and initiation phase. This stage consists of following activities.

Activity 1: Service prioritization

The government prioritizes and selects the services those need to be migrated to the cloud computing platform based on the requirements and feasibility report. Even if a service falls in the government priority, if it could not be delivered effectively online, or the stakeholders are less likely to use than its migration should be deferred. With the strategic imperative in place, government agencies 
must choose which parts of their IT environment, both legacy and new spending, to migrate to the cloud and, in each case, determine the appropriate cloud service and deployment model. We have designed a template for the service prioritization as shown in Figure 4. This template should be used while assessing the different criteria set for the services to be migrated. The following figure shows the government service prioritization process for the cloud based G2G e-government framework using three different scales, i.e., high, medium and low ranging from 1 to 3 . The sums are calculated and the services are ranked in descending order of the sum. The service with the highest total value has high priority and the least has low.

\begin{tabular}{|c|c|c|c|c|c|c|c|c|c|}
\hline \multirow{2}{*}{$\begin{array}{c}\text { Government } \\
\text { services }\end{array}$} & \multicolumn{7}{|c|}{$\begin{array}{l}\text { Prioritization criteria } \\
\text { Criteria value: }(\text { High }=3, \text { Medium }=2, \text { Low }=1)\end{array}$} & \multirow{2}{*}{$\begin{array}{l}\text { Government } \\
\text { services }\end{array}$} & \multirow{2}{*}{$\begin{array}{l}\text { High Total } \\
\text { Value }\end{array}$} \\
\hline & Cost & Impact & Workload & Compatibility & Sophistication & Value for citizen & Row total & & \\
\hline \multicolumn{10}{|l|}{ Service 1} \\
\hline \multicolumn{10}{|l|}{ Service 2} \\
\hline \multicolumn{10}{|l|}{ Service 3} \\
\hline \multicolumn{10}{|l|}{ Service 4} \\
\hline \multicolumn{10}{|l|}{ Service 5} \\
\hline \multicolumn{10}{|l|}{ Service 6} \\
\hline \multicolumn{10}{|l|}{ Service 7} \\
\hline \multicolumn{10}{|l|}{ Service 8} \\
\hline \multicolumn{10}{|l|}{ Service 9} \\
\hline \multicolumn{10}{|l|}{ Service 10} \\
\hline \multicolumn{10}{|l|}{ Service 11} \\
\hline \multicolumn{10}{|l|}{ Service 12} \\
\hline \multicolumn{9}{|l|}{ Service 13} & \multirow{2}{*}{$\begin{array}{l}\text { Low Total } \\
\text { Value }\end{array}$} \\
\hline Service 14 & & & & & & & & & \\
\hline
\end{tabular}

Figure 4. Service prioritization template.

Activity 2: Identify service delivery channels

Service delivery channel is essential for the execution of e-government services. One of the issues that we have found in the current e-government practice is the approach of the service delivery. Merely building a portal and hosting it would not gain stakeholders acceptance. Having appropriate delivery channels is the most desirable to acquire wider adoption of the offered e-government services. Therefore, the point of access to e-government services needs to be established. We have proposed various delivery channels-i.e., tele-centres, kiosks, private business partnership and rural municipalities as delivery channels. It is necessary to provide appropriate justification before choosing any deliver channels. Government could use all of them or some of them based on the availability and usability.

Tele-centres: The concept of tele-centres is already in use in some developing countries. A tele-centre serves as a community centre that is equipped with the computer and internet connection. Rural areas of developing countries, where people are less likely to have access to ICT tools, could benefit from tele-centres. Tele-centres are established by the government in the communities and managed by the member of the community. These centres could be used to enhance the skill of the local population and to motivate to use e-government services.

- Rural municipalities: These are smallest unit of governments and primary point of contact for the government service delivery. Computerization and connecting these municipalities to the internet would increase their efficiency and could better serve the local population.

- Kiosks: Kiosks machine are popular in the developed countries. Kiosks are self-service machine that people can use to take certain government services. Since these machines are not very expensive and easy to install, government can use them to deliver government services. These 
machines could be placed in the local libraries, government offices to reduce the workload on the staff and in the private business premise.

\section{Activity 3: Define the Electronic transaction processing model}

In the absence of the payment gateway, transaction processing model needs to be identified. It is imperative for e-government systems to have electronic transaction processing mode in place in order to achieve service automation. These models are based on the available technology in the particular country context. One of the possible solutions of the financial transaction could be collaborating with the private banks or other businesses to handle the monetary transaction. Generally private banks now days offer e-banking services which can be used to deal with payment processing by embedding their services within e-government portals.

- Electronic wallet: although developing countries lack payment gateways, many of the countries have private business those are providing electronic wallet services to the users. This could be one of the option for the government to embed their services in the government portal to accept payments.

- $\quad$ E-banking: Almost all of the corporate banks in developed or in developing countries provide e-government services. Government could collaborate with the banks for the payment handling.

- Private business: involvement of the private business as an agent to deliver certain government services to the stakeholders could be one of the options for payment handling in developing countries. Government could appoint agent companies to handle the payment sharing certain commission percentage. We have examined various e-government projects in the Asian countries to identify how the financial transaction is being handled. Among them we have found that Pakistan government initiative to engage private business as a franchise to handle money from the stakeholder is running successfully. According to the government portal www.e-sahulat. nadra.gov.pk, e-sahulat handles $23 \%$ of the Utility Bill market share with its 12,000 franchises.

Activity 4: Identify the cloud service model

At this stage, appropriate cloud service model needs to be chosen for the selected government services based on the needs. The service model is selected based on the services that are being migrated to the cloud. The proposed framework is used when there is already an electronic government system but could not achieve the goal because of the limited information communication technology infrastructure. Individual productivity software procurement for government department such as word processing could be replaced by software as a service (SaaS). However most of the application and system are custom made to meet individual government's need, the most used cloud service in e-government is infrastructure as a service (IaaS). Legacy system, government enterprise application those have dependencies with the operating system requires infrastructure as a service (IaaS).

Activity 5: Identify the cloud deployment model

Once the appropriate cloud deployment strategies have been developed and cloud service model has been selected the government need to decide what cloud deployment model they need to adopt. The framework supports the government to adopt appropriate cloud deployment model. Selection of the certain types of deployment model depends on several factors. Considering the cost and infrastructural factors we have found that the hybrid cloud deployment model would be appropriate for developing countries. The hybrid model would allow the government to keep their critical data on-premises and less critical data in the cloud platform.

Activity 6: Customization and configuration of the legacy system

This task identifies whether there is a necessity of customization of the existing services. The existing legacy system might need a customization before they could be migrated to the cloud 
environment. Therefore, this task supports governments to assess the selected e-government system to make appropriate customization to gain maximum potential benefit.

Activity 7: Migration

Once the activities in this stage are completed the system migration an integration process begins. The migration is a process of moving the existing electronic government system to the cloud environment. In relation to electronic government migration to the cloud (within the context of developing countries), the cloud vendor or third-party company could be employed to complete the migration process as it involves many technological issues that need to be handled by an expert. There are many issues that need to be considered while the traditional electronic government system is being migrated. The government needs to decide whether the legacy system needs to be re-engineered before migration to the cloud. The feasibility study should be done while re-engineering the legacy electronic government system to decide whether the system needs to be rebuild completely or the re-engineering would be sufficient for the migration. The migration process will be discussed in detail in the methodology section.

Stage 4: Evaluate: The final stage of the cloud based framework involves evaluation of the outcomes of the previous stage. Value creation is an important parameter that we have used to evaluate the framework. Value creation is a process of adding value to e-government services that the stakeholders acquire. The value of e-government services could be increased by providing citizen-centric, simple and affordable services. The different stakeholders of the electronic government; citizen, business, government and organizations are linked together, thus adding the value for one stakeholder benefits all. These stakeholders have their own perspective on the value creation. The value creation for the government is to save cost and time, gain wider e-government adoption from the stakeholders and minimize the resource wastage. The outcomes obtained from these activities are mapped to the framework goals to make decision whether to continue the cloud based G2G e-government or not. The flowchart in Figure 5 shows the comparison process that supports the government decision to adopt the plan.

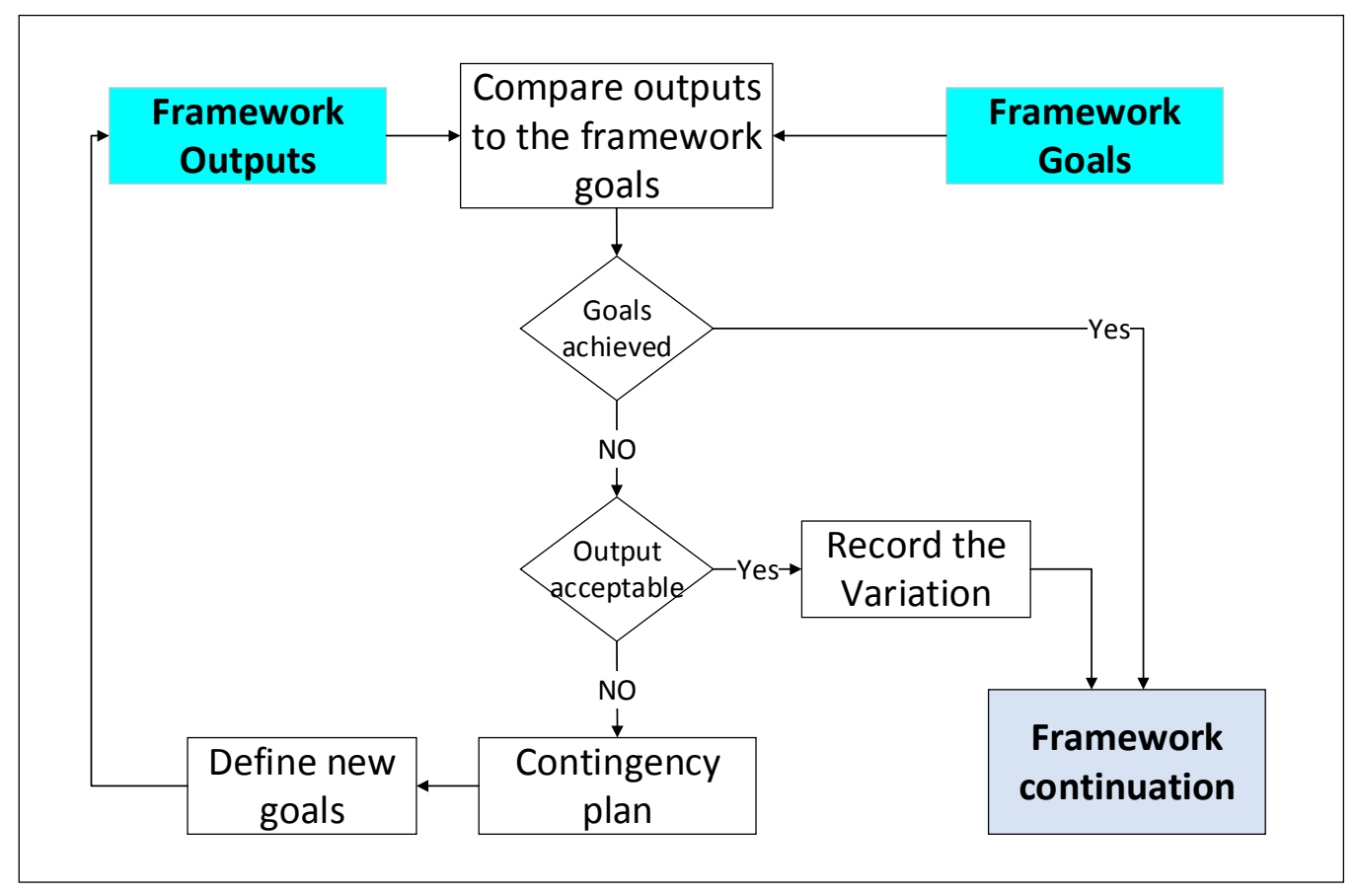

Figure 5. Evaluation of the framework goals. 


\section{Case Study}

We have adopted participatory action research approach to implement and evaluate the proposed framework. One of the rationales for adopting the participatory action research is the nature of this research that requires the interpretation of the findings in qualitative approach with reasoning rather than merely presenting quantitative data. Moreover, the action research provides high level of practical relevance to the subject being studied. Action research allows to gather data by employing various methods required i.e., observation, experiment, interview and written cases. We have utilized interview, observation and case study method to collect the data.

\subsection{Study Context}

The study context is Nepal as a developing country. Nepal is a landlocked country with vast geographical diversity and is characterized by a highly centralized government. Local administration is performed through numbers of administration districts. At present, it has 5 development regions, 14 zones and 75 districts, however it is going through a serious reform following constitutional assembly election in 2008 and 2013. E-government initiative in Nepal started in 2006, with funding from the Korea IT Industry Promotion Agency (KIPA). The government had announced the project called the electronic government master plan of Nepal, which has proposed 21 various electronic government projects with the estimated budget of 65 million US dollar. Later only 8 projects were selected for execution because of the insufficient fund. The Asian development bank granted support of 25 million US dollars and the Nepal government contributed only 6 million US dollars [24]. Studies on the effectiveness of these e-government projects in Nepal have found that the master plan has failed to achieve its objective [24,25]. Several issues have been encountered such as availability of the technology, budget, human resources and organizational structure while implementing the projects. Beside this, e-government services those are in existence also have several issues like accessibility, language, poor quality of information, lack of help and support, lack of integration of the government departments and lack of scalability and availability of the services [26]. Recently, the public service communication server for the services has crashed as it failed to handle an excessive number of requests from users [26].

\subsection{Area of Focus}

After the initial review of the current e-government project progress, we have focused our attention on the driving licensing unit of department of transport management. It has its own online portal that at present allows residents of the Bagmati Zone (one of Nepal's 14 zones) to apply for a driving license. However, the services of the online portal are only available during the office hour and only limited to the Bagmati zone. It also allows viewing of license detail and record of a user. Although the driving licensing department in the different zones uses their own legacy system, lack of integration and consolidated data across the departments in the different zones restrict the efficiency of the government services. From the preliminary contacts with the people in the department, we came to know that the existing system in the department for transport and license has been going through the reform to accommodate the changes in the recent government process following a local government body election.

\subsection{Study Objective and Hypothesis}

The aim of the case study is to analyse whether the proposed framework is able to address the current challenges faced by the e-government project in Nepal. In particular, the framework will be evaluated as to whether it is able to integrate the isolated e-government system (Data silos) in efficient (financially and technologically) way while supporting the government to provide services in more citizen-centric approach. We have set two hypotheses that will be tested against the findings of the study. 
Hypothesis 1: Government-to-government (G2G) approach would allow governments in developing countries to provide citizen-centric e-government services.

Hypothesis 2: The integration of the government departments for G2G e-government could be achieved by adopting cloud computing platform with less cost and time.

\subsection{Study Plan}

The study required the involvement of stakeholders from different dimensions (Government employee, ICT experts and cloud vendors and experts) from the beginning to the end of the project. Therefore, the first task was to identify potential stakeholders and ensure their involvement in the study. We firstly approached a government official in the driving license department. We have contacted one of the senior employees of the department for an appointment to discuss the project. After some informal conversation over the phone and via email, we made an agreement for the case study. We also made a list of cloud service providers (CSP) in Nepal who could be potential service provider for the project. From the initial conversation with the representative and other higher-level employees of the companies we have dropped some companies from the list as a potential stakeholder of the project as they do not fall within our criteria (the CSP should be able to provide different cloud service and deployment model). After the second round of contact with the companies, we have decided to approach Data Hub \& Network Pvt Ltd. (kathmandu, Nepal) to get involved in the study. Data Hub \& Network Ltd. is a new company in Nepal offering cloud based computing solution to enterprise and government agencies. The director of Data Hub \& Network Ltd. agreed to get involved in the pilot project by providing support with the human and technological resources for the project implementation. We had then arranged meeting with stakeholders from both side to discuss the framework and implementation plan. Data collection was done mainly from the brainstorming session, interview and observation made during the framework implementation process.

\subsection{Study Team}

The study team is formulated from members of the government ministry, experts from external supplier and main author of this paper. Among three government officials two of them are the top-level government employee in the department of driving license and one of the system developer from the department who have been directly involved in the project from the beginning. Four experts from the Data Hub \& Network Ltd. are also involved to support the implementation process of the framework. After brief introduction of the members they were allocated their responsibilities.

\subsection{Process}

We had begun the assimilation process by identifying government vision for cloud based e-government as shown in Figure 6. An informal meeting was held with the government employee to discuss the vision for implementing the framework. Later we have taken a more structured approach to gain insight into the subject domain. Semi-structured interviews have been conducted using loosely designed instrument to get as much information as possible. We have explained the vision of the cloud based G2G framework from the research perspective and encouraged the participant to share their views on the initially identified vision. Once the government vision for the cloud based e-government was decided, we have put forward our e-government maturity model that defines how e-government project should be assimilated to gain the maturity. After the brainstorming session, the members of the team have agreed that the in the context of Nepal (where there is no payment gateway available), the proposed maturity model would be best suited. Once the maturity model had been confirmed we moved to the approach of e-government. The maturity model itself defines the approach of e-government implementation in relation to developing countries. We have explained how government could achieve efficiency by integrating their systems in the different location. Therefore, the team members have agreed to adopt G2G approach. 


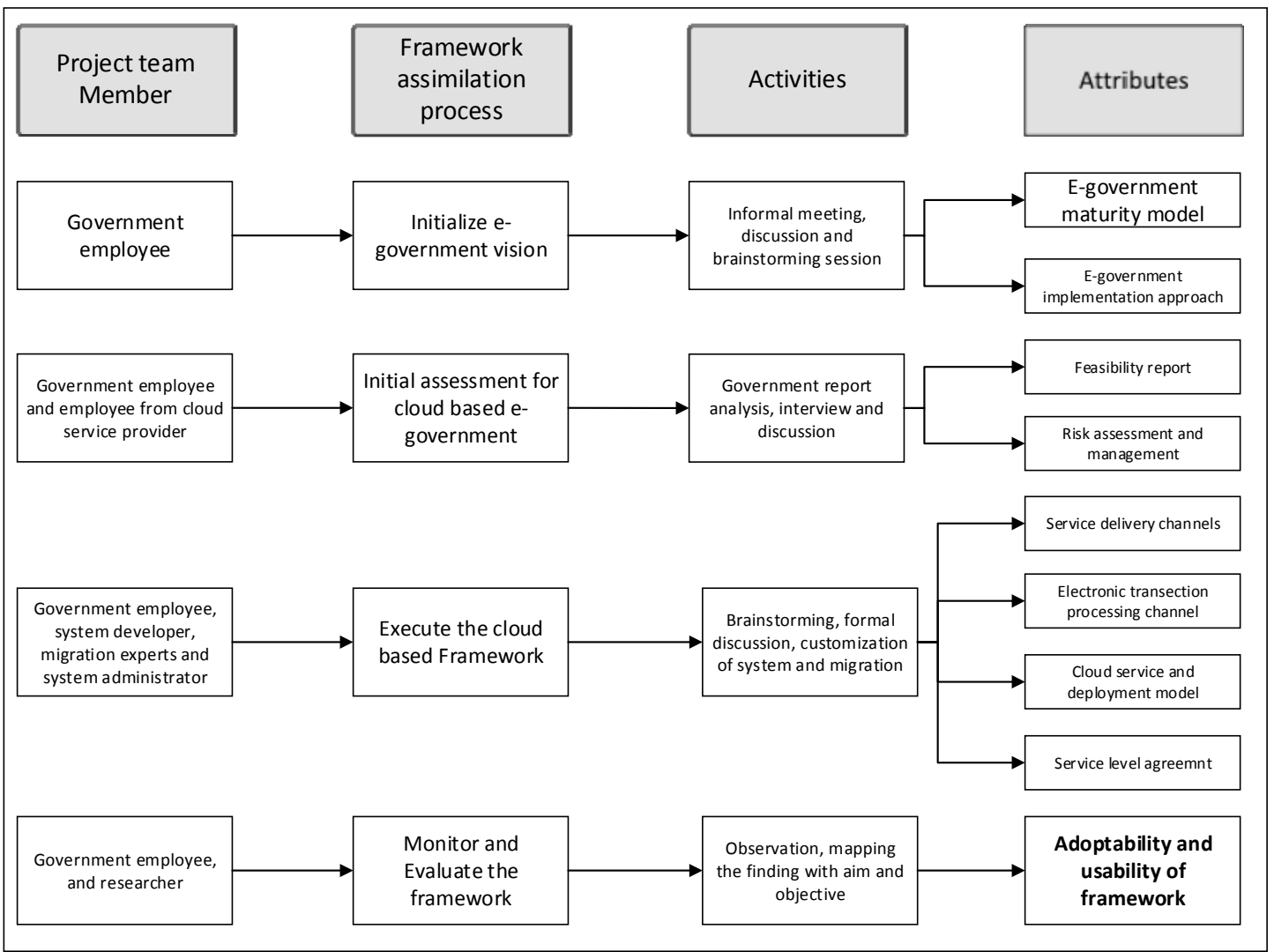

Figure 6. Case study design.

\subsubsection{Initialize}

Requirement Analysis

After e-government maturity model and approach has been decided, we had to identify the current e-government practice, issues as shown in Table 2 and the government expectation from the new system. We have performed requirement analysis to analyse the above mention factors. We had conducted a semi-structured interview with the driving license department official to capture the current status of e-government system in the department and their requirements have been recorded. These requirements have been conveyed to the system engineer and cloud expert from Data Hub \& Network Ltd. to identify appropriate cloud service and deployment model.

Table 2. Issues in the current system and government requirements.

\begin{tabular}{cc}
\hline Issues in Current System & Requirements \\
\hline $\begin{array}{c}\text { Hardware failure, Power interruption, Data centre } \\
\text { outages, Cost of managing the hardware and } \\
\text { software, servers are outdated (win 2003), isolated } \\
\text { systems, high cost on networking }\end{array}$ & $\begin{array}{c}\text { Integration of the systems in the different location, } \\
\text { availability of the service round the clock, minimizing the } \\
\text { overall cost, collaboration among the department, continuity } \\
\text { of the legacy system, citizen oriented services }\end{array}$ \\
\hline
\end{tabular}

\section{Cost Benefit Analysis}

The current practice of the IT resources procurement uses a fixed price model and the department budgets to procure the government IT resources. However, lack of the certainty in relation to the cost of having cloud computing resources made the government official worried. This concern has been addressed by performing cost benefit analysis that provides comparative analysis between what is the government investment and what would the government get in return. 
We acquired details of government annual expenditure in the licensing department for the e-government project and detailed the cost of hardware and software procurement, the cost of maintenance and updates, the cost of IT staff salaries and their training and the cost of managing the data centres that the department maintains. We have found that the department spends money in procuring the distributed system as required by the different offices in the different regions, however, lack of unified and enterprise resource planning in the department has excessively increased the expenses while delivering low value. Furthermore, we have requested an estimated quote from Data Hub \& Network Ltd. for the proposed government services migration to the cloud platform and the running cost then compared those costs with the current IT spending of the department to establish its viability and the Return on investment (ROI).

\subsubsection{Assess}

Once the government vision, e-government approach and maturity model had been agreed, we moved to the initial assessment for cloud based e-government stage. The aim of this stage is to explore whether the government department have enough resources to accept the proposed model. We have conducted a feasibility study and cloud based e-government risk assessment.

\section{Cloud Feasibility Analysis}

We have considered three different parameters, technological, financial and organization in our assessment those have a direct impact on the project. The analysis has identified some issues those could have a negative impact on the project. We gathered data from government report in relation to their IT infrastructure and budget allocation for e-government systems. We conducted an informal discussion among the member of the project team, that involves the system designer, migration expert and government official. The cloud migration expert presented the technical requirement those need to be met to adopt the cloud based e-government. The findings of the government report have been shared with the cloud expert and system designer to analyse whether the current systems could be migrated to the cloud. The financial feasibility has been analysed based on the outcome of the cost benefit analysis. Finally, government employee from the driving license and the management level employee from the Data Hub \& Network Ltd. had meetings to identify whether their organizational interest contradicts with each other. Based on the feasibility study, we concluded that the driving licensing department has sufficient resources available to adopt the framework. Therefore, it is identified that the project could go ahead without any problem. The key findings are shown in Table 3 .

Table 3. Feasibility study finding.

\begin{tabular}{|c|c|}
\hline Parameters & Findings \\
\hline Technological & $\begin{array}{l}\text { - } \quad \text { Department have servers and legacy system. } \\
\text { - } \quad \text { Web applications are already running. } \\
\text { - } \quad \text { Driving license department in the different zonal headquarter have } \\
\text { internet connectivity. }\end{array}$ \\
\hline Organizational & $\begin{array}{l}\text { - } \quad \text { Have enough human resource to involve in the project. } \\
\text { - } \quad \text { Organizational policies do not contradict with the project aim. } \\
\text { - } \quad \text { Government official are keen to implement the framework. } \\
\text { - } \quad \text { Will gain support from the CSP for training the IT staff to adopt the change. }\end{array}$ \\
\hline Financial & $\begin{array}{l}\text { - Driving licensing department have been allocated budget for regular upgrade and } \\
\text { maintain of their IT system. } \\
\text { - Since the migration of the government system was only the pilot test there is no } \\
\text { need of budget allocation. } \\
\text { - The CSP has provided estimated cost of the cloud service acquisition and the } \\
\text { driving likening department confirms that it is within their budget. }\end{array}$ \\
\hline
\end{tabular}


Although the proposed framework is technically viable to implement, the feasibility report highlights some issues that need to be addressed before implementation of the framework. The internet speed is very slow; therefore, the government department needs dedicated internet connection that allows smooth communication among the system on premises and on cloud. Similarly, the department needs to procure alternative energy solution to power the on-premises IT equipment and the data centre.

\section{Risk Assessment and Management}

The feasibility report shows that with the minor changes the government department is ready to move to the cloud based e-government. However, the government has some strict policies in relation to the privacy and security of the data and information that is being migrated to the cloud. To assure the government official of any concern in relation to the privacy, security and other issues we have conducted cloud risk assessment. Table 4 shows the risks identified in cloud migration in the study context. Technological risks are considered highly critical risk.

Table 4. Risk assessment for cloud service adoption.

\begin{tabular}{|c|c|c|}
\hline Category of Risk & Risk Type & Impact on the Governance \\
\hline \multirow{3}{*}{ Organizational } & $\begin{array}{l}\text { Supply chain } \\
\text { failure }\end{array}$ & $\begin{array}{l}\text { The supply chain failure could lead to the interruption of the service as the } \\
\text { CSP might have been procuring some of their service through third party. }\end{array}$ \\
\hline & Service termination & $\begin{array}{l}\text { Since there are very few companies in Nepal those offer the cloud } \\
\text { computing services and their client-tale is not significant there is always } \\
\text { a risk of service termination. }\end{array}$ \\
\hline & Lock in & $\begin{array}{l}\text { The data lock in situation could likely occur in the absence of an alternative } \\
\text { service provider. }\end{array}$ \\
\hline \multirow{4}{*}{ Technological } & $\begin{array}{l}\text { Security and } \\
\text { privacy }\end{array}$ & $\begin{array}{l}\text { Security and privacy is the one of the main risk associated with the cloud } \\
\text { computing. The CSP has certain control over the systems hosted in the } \\
\text { cloud, therefore their potential impact on the confidentiality and the } \\
\text { integrity of the data could not be denied. }\end{array}$ \\
\hline & Isolation failure & $\begin{array}{l}\text { The shared resources in the cloud computing can expose the confidential } \\
\text { data to the other tenants. Failure of the isolation of the resources could } \\
\text { make the government system vulnerable to attack. }\end{array}$ \\
\hline & Availability & $\begin{array}{l}\text { The government official shows concern in relation to the availability of the } \\
\text { service. }\end{array}$ \\
\hline & $\begin{array}{l}\text { Unauthorized } \\
\text { access to premise }\end{array}$ & $\begin{array}{l}\text { Since the data and information not in held in the government premise the } \\
\text { official have concern over the unauthorized access to the physical location } \\
\text { of the data centre. }\end{array}$ \\
\hline \multirow[t]{2}{*}{ Business } & Data protection & $\begin{array}{l}\text { The measures applied in relation to the data protection by the CSP which is } \\
\text { difficult to check, therefore lack of the mechanism to check whether the CSP } \\
\text { is complying with the data protection policies, could lead to legal } \\
\text { challenges. }\end{array}$ \\
\hline & Licensing & $\begin{array}{l}\text { The department yet to decide whether the software and application they } \\
\text { are using at present might violate the terms and condition by migrating } \\
\text { them to the cloud. }\end{array}$ \\
\hline
\end{tabular}

We have used customized information assurance framework as described in ENISA (2009) to get assurance whether the CSP has sufficient measures to address the government concern. The answers received from the framework are documented in master service agreement (MSA) and Service Level Agreement (SLA) to resolve any conflict in future.

To better address the government concern of their data and information is handled securely we have divided the security measures in two categories.

- Physical security:

Physical security would assure the government that the data and information are held in a secure location where only authorized people have permission to get access. The data centre of the Data 
Hub \& Network Ltd has been visited to see whether they have an appropriate mechanism in place to secure the data and information. The following observation has been made.

- $\quad 24 * 7$ CCTV monitoring of the premise

- Biometric authentication system in place to enter into the premise

- $24^{*} 7$ electricity backup

- Second data centre is located outside the valley for disaster management

- $24^{*} 7$ technical support staff is available to address any issues in system

- $\quad$ ISO 27001:2013 certified data centre

- Logical security:

Logical security would assure the government that the data and information within the cloud environment is secure from the logical threat i.e., hacker, intruder and virus. The following but not limited to measure have been put in place.

- Virtual private cloud

Since we were using public cloud we have decided to acquire a virtual private cloud within the public cloud environment to minimize isolation failure issues. A virtual private cloud (VPC) is a logically isolated cloud within the public cloud that provides certain level of isolation among the uses. Therefore, the virtual private cloud would reduce the risk of interference and unauthorized access by the intruder. The Data Hub \& Network Ltd. has confirmed in the SLA that the government virtual machine will be isolated and networked using virtual local area network (VLAN) using virtual switches. The VLAN allow only specific preconfigured traffic to access the VM through virtual switch port that would add extra layer of security to the data. However, there is always a risk of security even in the virtual private cloud as e-government systems are open to public use and it carries inherent risk. To minimize the security risk caused by the public instances we have decided to use hardware virtual private network between the on-premises system and the systems in the cloud. Hardware virtual private network provide ability to configure and filter the inbound and outbound traffic at subnet level.

- Data encryption:

Data encryption technique has been applied in order to secure the confidentiality of the data in the case the data is compromised. The data encryption techniques have been designed to protect the data resident in the system and the data in the motion. The data residing in the virtual machine have been encrypted using a feature provided by vSphere 6.5 .

\subsubsection{Execute}

This stage involves most of the technical details. The members from the Data Hub \& Network Ltd. technical team had taken the charge to perform the migration activities. Security measures have been strictly followed while migrating to the cloud.

\section{Service Delivery Channels}

As proposed within the framework we had a meeting with the government official to discuss the proposed e-government service delivery channel. From our preliminary investigation and survey, we found that the 45 percent of the government service beneficiaries do not have access to the computer and internet. Similarly, 30 percent of them could not operate the computer and among them, 5 percent have never seen the computer. Therefore, different delivery channels need to be established to allow access to the services. Following the recent election, the local government has started functioning and they have enough human resource to serve the citizens. 45 percent of the smallest 
local government administrative unit Rural Municipality (RM) does not have access to computers and internet connection. The first priority for the government is to computerize the units and connect them with the internet. After some round of discussion, we all agreed that the computerization and connecting the Rural Municipalities is the best approach to deliver e-government services. As shown in Table 5, the government official found it practical to establish community Tele-centres, computerization of the libraries and involving private companies to deliver services in the rural area. Later, we came to know that the government of Nepal has invited foreign investment to establish the data centre in the rural area of Nepal and aims to connect the 75 district headquarters with high-speed internet. However, this does not have any relation with our project.

Table 5. Delivery channels for e-government services.

\begin{tabular}{|c|c|}
\hline Current Practice & Agreed Delivery Channels \\
\hline - $\quad$ e-government portal & e-government portal \\
\hline \multirow[t]{4}{*}{ Manual service provided from the government office (Paper based) } & Rural municipalities \\
\hline & - $\quad$ Tele-centre \\
\hline & - $\quad$ Libraries \\
\hline & Private business \\
\hline
\end{tabular}

Among the different delivery channels for e-government services, the most feasible channel of delivery is rural municipalities and tele-centres. Rural municipalities are already functioning and delivering paper based government services to the stakeholders. However, these services are limited to very basic as they have minimal authority to do so. As e-government services become automated, all that rural municipalities need is to have access to the internet and use of computers. After the framework has been implemented, we have found that the municipalities those who have access to the internet and computer could obtained more than 70 percent of efficiency in service delivery. Tele-centres are yet to be established; however, the feedback we have received from the community was very optimistic. Tele-centres are some form of community centre those are equipped with the computer and internet connectivity. These centres need to be established by government in the community and then managed by the member of the community. The tele-centres could be used for different purposes i.e., to train the local community to use e-government services, to get update about the local government activities and to use the ICT services. These centres could play a crucial role in the local community especially in those communities where people are less able to invest in the ICT tools.

\section{Electronic Transaction Processing Model}

Since there is no payment gateway available in Nepal, we have approached some of the private companies to discuss how their services could be used in e-government. Among the companies, E-sewa, Khalti and Pravu Bank agreed to discuss the possibility of expanding their services in e-government as shown in Table 6. E-sewa has been providing electronic wallet service to the individual and allows them to pay different types of bill i.e., internet bill, telephone bill, purchase cinema ticket and online payment to some supermarket. After the initial discussion with the $\mathrm{CEO}$ we arranged another meeting that included the government official and representative from E-sewa. The representatives have presented their business model that shows how they provide their service for a small amount of commission. They agreed to have further meeting to discuss the terms and condition to handle the driving licensing fees from the customer. The commission for the handling fees for the services needs to be discussed between the company and the driving licensing department. The company currently charges 2.5 percent commission per transaction of the total amount, however this could be discussed in detail and could be reached in mutual understanding in relation to the fee handling for the government department. The government official and bank employee agreed to have next meeting to discuss and agreed the handling fee and sign and memorandum of understanding. 
Table 6. Electronic transaction processing method.

\begin{tabular}{cc}
\hline Current Transaction Processing & Agreed Method \\
\hline Nepal government does not have payment gateway therefore does not & E-sewa \\
handle any financial transaction online. & Khalti \\
& Banks \\
\hline
\end{tabular}

To see how these transaction modes perform and what impact they make on stakeholders' decisions to use e-government services, we embedded the services of E-sewa for payment handling within the driving licensing portal. While in the current e-government portal the user could only fill the form online and have to go to the local government office or to the bank in order to complete the transaction, use of E-sewa would allow the stakeholders to pay the application fee instantly. It saves both stakeholders and government time that is required to process the transaction. Although use of E-sewa in portal certainly attracted more user, there are some serious concern has been raised by some of the stakeholders. The stakeholders require opening an account with the E-sewa and deposit fund in order to pay by using E-sewa service. Therefore, this could not be as effective as debit or credit card payment.

\section{Cloud Services and Deployment Model}

The driving licensing department was using windows servers 2008 which needed to be replaced to accommodate the government requirement. The government official initially wanted to move file, email and application servers to the cloud and keep the database and directory service server on premises. However, there were dependencies and middleware used among the server and moving part of the system to the cloud would be very complex as it would have to go through the re-configuration and networking to allow them to communicate efficiently. Only moving part of e-government system might not perform well in the new environment, therefore the existing servers and the virtual machines need to be migrated to the cloud environment. The cloud expert from Data Hub \& network Ltd. and government system architect agreed to adopt infrastructure as a service model. The Data Hub \& Network Ltd. agreed to train the government IT staff in relation to the day to day operation of the cloud based system i.e., networking in cloud, security, configuration of the servers and new application etc. Until government staff are fully trained, the day-to-day operation of the cloud environment would be supported by the staff of Data Hub \& Network Ltd. Data Hub \& Network Ltd. has also agreed to lease a dedicated high-speed internet connection to the department to overcome bandwidth issues.

Data Hub \& Network Ltd. had given an option to the government official where they procure all the hardware and software on the government premise and manage it for the government. However, this is not a cost-effective option. The other option was to have dedicated private cloud computing infrastructure allocated off premise and the legacy and some other services remain on premise. The official from the licensing department chose the second option that is cost effective and could be acquired in less time. Therefore, the hybrid model of the cloud was adopted, where some services of e-government will be migrated to the cloud and some of them remain on government premise. In the brainstorming session, the government employees were interested to know the possibility of establishing their own private cloud infrastructure which could be shared among the different government departments. A detailed feasibility study is required in order to decide whether a private cloud deployment model can be adopted.

\section{Service Level Agreement (SLA)}

Since the government works differently than the private enterprises the decision to migrate e-government services to the cloud has to go through a stringent procedure. The government has their own obligations and follows a tightly guided process in relation to procure the cloud services and it has own unique requirement in relation to the cloud services that need to be strictly met. These concerns 
have been addressed by drafting the Master Service Agreement (MSA) and Service level agreement (SLA). From the project initiation, the main concern of the department official was the security of the data and information in the cloud. Furthermore, the availability of the service and the elasticity for the scalable of services are the secondary concern. The government thus wanted to document the promises made in terms of the services provided by the CSP. After the mutual understanding among the government official and the management employee at Data Hub \& Network Ltd. a memorandum of understanding has been drafted, however, it has not been signed by either of the party at this time. The service level agreement (SLA) has been drafted according to the ISO/IEC 19086 that includes the clauses shown in Table 7.

Table 7. Clause included in service level agreement (SLA).

\begin{tabular}{cl}
\hline Clause & \multicolumn{1}{c}{ Description } \\
\hline Accountability & $\begin{array}{l}\text { The clause discusses how the CSP complies with the government policy in relation to the } \\
\text { data and information processing in the cloud. }\end{array}$ \\
\hline Agility & $\begin{array}{l}\text { This section provides detailed description of the elasticity and the scalability of the service } \\
\text { as required by the department. }\end{array}$ \\
\hline Assurance & $\begin{array}{l}\text { Availability and reliability of cloud computing service, capacity to tolerate fault and } \\
\text { addressing other issues when required is included under this clause. }\end{array}$ \\
\hline Financial & $\begin{array}{l}\text { This section provides detailed cost of migrating and running e-government services in } \\
\text { cloud platform. It also specifies whether there would be variation in cost in future. }\end{array}$ \\
\hline Performance & $\begin{array}{l}\text { The performance related conditions are documented under this cloud. This cover the } \\
\text { service response time, interoperability and other cloud computing performance related } \\
\text { subjects. }\end{array}$ \\
\hline Security and \\
privacy & $\begin{array}{l}\text { All the security and privacy concern of the department and assurance from the CSP have } \\
\text { been documented under this clause. That covers safeguard of government data, keeping } \\
\text { the privacy intact and securing the critical data from damage. }\end{array}$ \\
\hline Support & $\begin{array}{l}\text { This clause covers how the CSP would support the government employee throughout the } \\
\text { migration process. This further describes the services that the department receives once } \\
\text { the system is migrated. }\end{array}$ \\
\hline
\end{tabular}

\section{Customization and Configuration of the Legacy System}

This task runs along with the task of identifying the service and deployment model of the e-government. Members from the cloud migration expert, system administrator, system developer and government employee were involved in this task. The existing e-government system was assessed for its compatibility in the cloud environment, the growth plan, scalability and security requirements. A third-party cloud assessment tool SOASTA was utilized to assess how the legacy system would handle the workload after it has been transformed into a web application and migrated to the cloud. The driving licensing department web portal was load tested by simulating the requests from user in various locations. The web portal successfully handled a hundred thousand requests at a time. Some configuration tuning parameters were identified and agreed among the members of the case study in order to gain the maximum potential benefits of the cloud computing platform. An assessment chart was generated with the findings of the test and recommended actions.

\section{Migration}

A team of cloud migration expert from Data Hub \& Network Ltd who were involved from the beginning of the project had a meeting with cloud architect, system administrator, application developers in the government department and people in the finance who manage the IT budget. The team was actively engaged in the migration process. After the initial assessment of the application using the SOASTA tool, we used an application performance management (APM) tool, Dynatrace. The reason for using the tool was, it allows 30 days free use as a trial and seems recommended by huge numbers of their clients. The tool provides an overall picture of the entire existing IT environment, 
servers, storage networking, application and dependencies among them. We also used CloudEndure tools that allow replication of the server, its migration and the testing of it before the on-premise server function is cut off and the server in the cloud becomes alive. This was very crucial as we did not want to alter the exiting e-government process, rather the purpose of the migration was to demonstrate how the proposed framework can add value to the existing e-government system and address the current issues. Therefore, the migration of the actual workload to the cloud could be decided by the government authority at a later stage.

\subsubsection{Evaluate}

The purpose of this stage is to evaluate whether the framework is able to meet its objective or not. The system was monitored for its performance, productivity and efficiency. The outcomes were matched against the service level agreement and the study objective. The government employees were focused in whether the system is able to deliver output according to the service level agreement; however, we were more interested to assess the framework against the research aim and objectives. Therefore we have broadened the criteria of evaluation to include the aim and objective of the framework. We found that the framework was able to effectively integrate the isolated system in less time and cost. E-government approach proposed by the framework is able to increase the efficiency of the government services while making the services more citizen-oriented.

\section{Discussion}

From the case study findings, we have made several observations in relation to the usability and adoptability of the cloud based e-government in the aforementioned study context. We found that the results have positively supported the study hypothesis. However, the framework needs to be fine-tuned and further investigated to generalize and evaluate its usability in different contexts. The discussion in this section summarizes our overall observation.

- $\quad$ G2G approach for Citizen-centric e-government services:

The empirical evidence acquired from the study strongly support the argument that the G2G approach would be best for providing effective government services to the stakeholders in developing countries. G2G approach allowed the different government departments efficiently reducing the replication of the work and effort. Officials at the regional government office in the Seti zone were able to process the driving license application without having to manually contact the head office for any adverse driving history of the applicant. This allows the government officials to make an immediate decision on an application. This has saved the stakeholder's time and the government officials were able to process three times more application than before. While the study shows that the framework effectively addressed the current challenges of e-government, addressing some of the issues will require more time and resources. One of the issues that needed to be addressed to reap the full potential benefit from the proposed framework is the establishment of delivery channels. Delivery channels still remain a major challenge for developing countries in relation to providing effective e-government services. No matter how sophisticated technology the government has, it requires citizen's involvement to become successful. Although the framework has defined several e-government delivery channels, the government requires a significant amount of time and resources to establish the entire proposed delivery channel. In relation to developing countries, the development projects are time-consuming and influenced by many different parties. Therefore, there is no guarantee that the government will establish the delivery channels. However, the government departments will still benefit from the integrated system. Even though the service is provided from the limited channels, the integration would significantly reduce the time of service delivery. Furthermore, the lack of payment gateway also limits the potential benefit of the framework. Although there are some private companies interested in providing the payment handling service for a small amount of commission, lack of government policy 
and laws does not currently allow in doing so. Therefore, appropriate government policy is required to address the issues.

- Cloud computing platform for e-government system integration

The framework has supported the smooth integration of the government system that was fragmented in the different geographical location. The database has been interconnected to form a centralized federated database that could be accessed by the driving licensing department in a different zone of the country. The integration has increased the speed of driving license application authentication process by 70 percent. This could be further reduced by another 20 percent if the other government departments-i.e., police and health services-also have a stake in the decision-making process. Furthermore, it has also minimized the probability of obtaining a license by providing false detail. The driving record could be accessed by the government official regardless of the geographical location that allows them to assess the application more effectively and reduce the chances of error. During our study, we found that some of the government departments are using Wide Area Network (WAN) to integrate their systems in the different locations, however, this was getting too complicated as the government began to expand its departments. Case study results show that the integration of the different system in the different location can be achieved with minimal effort reducing the burden of maintaining the complex and costly WAN. We have integrated the legacy system used by the driving licence office of Seti Zone to the Bagmati Zone. Both systems performed well and acted as a single system that minimized the burden of procuring individual ICT equipment and building ICT infrastructure in each office. Therefore, the hypothesis one is satisfied.

There remain issues with the use of CSP in the context of Nepal. From the interview and brainstorming sessions, we observed that the government officials have some concern relating to CSP. The government procurement process is complex that requires adherence to certain criteria. Limited numbers of CSPs make it difficult for the government to shop for the best possible deal from cost and technology perspective. We found that the government officials are not able to procure the cloud services from the offshore companies because of the government data security and privacy policy. Therefore, in the long run, it is advisable for the government to establish their own private cloud infrastructure that could be shared among the government departments.

- $\quad$ E-government project implementation time and cost

One of the main issues with e-government project in the context of Nepal is the amount of time required to implement. It has been 10 years since Nepal has initiated its e-government program, however a very little work has been done. Most of e-government project has been supported by the Korean government's aid. Only one datacentre is functioning at this time that provides server co-location service to the government department. The proposed framework has successfully addressed this challenge by reducing the time of project implementation. We have completed our project within 3 months; however, this does not include the time that is required to develop database and applications.

The cloud based e-government would save the driving licensing department 68 percent of their current spending to establish, maintain and operate their services. Meanwhile, it will increase the efficiency by releasing the pressure of day-to-day management of their IT system; those resources could be used in some other productive work. Beside the monetary cost, we believe the servers hosted in the cloud would deliver more efficiency to the department. It will reduce the server downtime and avoid the lack of service availability and risk of damaging the IT infrastructure because of the data centre power interruption. Similarly, the scalability of the computing resources would be able to handle the variation of the server loads efficiently. Another important aspect we have considered is the implementation time. Especially when the government department needs to expand their services to the different geographical location, the time required to establish the entire infrastructure is extremely high. Furthermore, the connectivity among these systems creates another difficulty in 
terms of technology and cost. In contrast, the expansion and reduction of the computing resources to meet the changed need of the department are almost instantaneous on the cloud variant. Therefore, considering all the above factors, the project has a high probability of success.

- $\quad$ Comparison with the other study results

We have compared the study results with the previous study to generalize the findings and also compared the outcomes of the case-study with the current e-government practice in Nepal and other countries. We have used e-government project cost, efficiency in the government process, citizen participation in e-government activities and e-government project implementation time as a parameter to compare whether the proposed framework support the government to achieve the above parameters.

The case study findings have concluded that the proposed framework would bring efficiency in the government process and support the government to make their service more citizen-centric. Despite the issues found in the cloud based e-government i.e., security and privacy, availability of the services, the findings have suggested that cloud computing would hugely support successful e-government project implementation. We have found that using cloud based e-government, the government could save almost 50 percent of their IT spending that is required to procure ICT tools and to manage those tools. Pokharel \& Park [27] said that cloud computing provides a cost-effective e-government project implementation platform in less time while supporting the government to maintain Green-ICT. Similarly, Wyld [9] found that increasing size of budget required to procure hardware and software will continue to drive governments towards cloud computing.

Furthermore, the findings show that the proposed e-government services delivery channels have supported the government to gain wider user participation in e-government service adoption. People have more choices and could use e-government services as per their ease. The findings of Bokhari [28] in relation to e-government delivery channels partially relate to the case study findings. His research shows that after involving private companies in e-government service delivery and establishing Kiosk in different location, the government has achieved more than 60 percent user involvement in e-government services.

\section{Conclusions}

Cloud based e-government models can effectively support developing countries to deliver better services with limited budget constraints and at the same time enhance efficiency by speeding up the service delivery process. While e-government projects in developing countries are struggling to sustain, we proposed an alternative e-government implementation framework that supports governments in developing countries to leverage their existing ICT infrastructure for successful e-government projects execution. We have found that the majority of the existing e-government frameworks are implementation centric that has increased the risk of losing the acceptance of the user. The proposed work considered adoption aspects of e-government project that justifies how and why the users' involvement is necessary for e-government activities. Another novelty of the work is the introduction of the citizen centric e-government services delivery approach through government-to-government (G2G) dimension. The framework discusses why the integration of the government department is crucial to deliver citizen centric service in developing countries and how it can be achieved. To demonstrate the applicability of the framework, we applied the framework to a real migration use case with a promising result. We found that the government-to-government (G2G) approach was better aligned with the users' needs. The government departments were able to interact and collaborate effectively for a better service delivery within less time and efforts. Since the majority of the users of e-government services in developing countries have limited ICT infrastructure access, the G2G approach supports offering the services through the various delivery channels and provides a cost effective integrated solution.

Our study concluded that the integration of the different e-government services and functions before the transaction stage is required in order to provide citizen-centric services in the context of developing countries. The cloud based G2G framework could be implemented for the betterment 
of the traditional e-government projects or to implement or initiate new e-government project. The importance of the framework in the given country context became more crucial as the government of Nepal is going through the political reform. Although the framework has been validated by employing reliable research parameters, we understand that a single case study is not adequate to generalize the finding and determine the applicability. More studies are required to further examine the framework in different scenarios for its validity. We are also planning to work for defining a guideline and checklist so that the framework could provide better hands-on support to the users.

Acknowledgments: We would like to thank the driving licensing unit staff, department of transport management and project team members of Data Hub \& Network Ltd, Nepal.

Author Contributions: Pusp Raj Joshi and Shareeful Islam have contributed to the design and development of the proposed framework, concepts and process. Pusp Raj Joshi has set up the case study and performed the case study. Syed Islam contributed review the whole paper and provided feedback with the framework.

Conflicts of Interest: The authors declare no conflict of interest.

\section{References}

1. Palvia, S.C.J.; Sharma, S.S. E-government and e-governance: Definitions/domain framework and status around the world. Int. Conf. E-Gov. 2007, 3, 1-12.

2. Heeks, R. Most eGovernment-for-Development Projects Fail: How Can Risks Be Reduced?; Institute for Development Policy and Management, University of Manchester: Manchester, UK, 2003; Volume 14.

3. Al-Hujran, O.; Al-Debei, M.M.; Chatfield, A.; Migdadi, M. The imperative of influencing citizen attitude toward e-government adoption and use. Comput. Hum. Behav. 2015, 53, 189-203. [CrossRef]

4. Dada, D. The failure of e-government in developing countries: A literature review. Electron. J. Inf. Syst. Dev. Ctries. 2006, 26, 1-10.

5. Lessa, L.; Negash, S.; Belachew, M. Steering e-government projects from failure to success: Using design-reality gap analysis as a mid-implementation assessment tool. In Emerging Issues and Prospects in African E-Government; IGI Global: Hershey, PA, USA, 2014; pp. 143-156. [CrossRef]

6. Magro, M.J. A review of social media use in e-government. Adm. Sci. 2012, 2, 148-161. [CrossRef]

7. Syamsuddin, I. Evaluation of e-government initiatives in developing countries: An ITPOSMO approach. Int. Res. J. Appl. Basic Sci. 2011, 2, 439-446.

8. Farzali, E.; Kanaan, G.; Kanaan, R.K.; Atieh, K. E-Government in Syria: Obstacles and Interoperability Framework. In Handbook of Research on E-Government in Emerging Economies: Adoption, E-Participation, and Legal Frameworks; IGI Global: Hershey, PA, USA, 2012; pp. 212-236.

9. Wyld, D.C. The cloudy future of government IT: Cloud computing and the public sector around the world. Int. J. Web Semant. Technol. 2010, 1, 1-20.

10. Hashemi, S.; Monfaredi, K.; Masdari, M. Using cloud computing for e-government: Challenges and benefits. Int. J. Comput. Inf. Syst. Control Eng. 2013, 7, 596-603.

11. Low, C.; Chen, Y.; Wu, M. Understanding the determinants of cloud computing adoption. Ind. Manag. Data Syst. 2011, 111, 1006-1023. [CrossRef]

12. Kshetri, N. Cloud computing in developing economies. Computer 2010, 43, 47-55. [CrossRef]

13. Top Strategic Predictions for 2018 and Beyond. Available online: http://www.gartner.com/technology/ research/predicts/ (accessed on 5 July 2017).

14. Zhang, W.; Chen, Q. From E-government to C-government via cloud computing. In Proceedings of the 2010 International Conference on E-Business and E-Government, Guangzhou, China, 7-9 May 2010; pp. 679-682.

15. Wang, L.; Von Laszewski, G.; Younge, A.; He, X.; Kunze, M.; Tao, J.; Fu, C. Cloud computing: A perspective study. New Gener. Comput. 2010, 28, 137-146. [CrossRef]

16. Smitha, K.K.; Thomas, T.; Chitharanjan, K. Cloud based e-governance system: A survey. Procedia Eng. 2012, 38, 3816-3823. [CrossRef]

17. Ismail, M.U.; Islam, S.; Ouedraogo, M.; Weippl, E. A Framework for Security Transparency in Cloud Computing. Future Int. J. 2016, 8, 5. [CrossRef]

18. Mukherjee, K.; Sahoo, G. Cloud computing: Future framework for e-Governance. Int. J. Comput. Appl. 2010, 7, 31-34. [CrossRef] 
19. Islam, S.; Ouedraogo, M.; Kalloniatis, C.; Mouratidis, H.; Gritzalis, S. Assurance of Security and Privacy Requirements for Cloud Deployment Model. IEEE Trans. Cloud Comput. 2015. [CrossRef]

20. Chanchary, F.H.; Islam, S. E-government based on cloud computing with rational inference agent. In Proceedings of the High Capacity Optical Networks and Enabling Technologies (HONET), Riyadh, Saudi Arabia, 19-21 December 2011; pp. 261-266.

21. Islam, S.; Fenz, S.; Weippl, E.; Kalloniatis, C. Migration Goals and Risk Management in Cloud Computing: A Review of State of the Art and Survey Results on Practitioners. Int. J. Secure Softw. Eng. 2016, 7, 44-73. [CrossRef]

22. Goel, S.; Manuja, M.; Dwivedi, R.; Sherry, A.M. Challenges of technology infrastructure availability in e-governance program implementations: A cloud based solution. J. Comput. Eng. 2012, 5, 13-17.

23. Islam, S.; Fenz, S.; Weippl, E.; Mouratidis, H. A Risk Management Framework for Cloud Migration Decision Support. J. Risk Financ. Manag. 2017, 10, 10. [CrossRef]

24. Rupakhetee, K.; Heshmati, A. Rhetoric vs. Realities in Implementation of E-Government Master Plan in Nepal. Developing E-Government Projects. In Developing E-Government Projects: Frameworks and Methodologies; IGI Global: Hershey, PA, USA, 2013.

25. Shakya, S.; Kharel, P. Comparative Study of Electronic Government Infrastructure of Nepal with SAARC Nations. In Proceedings of the 2013 International Conference on E-Technologies and Business on the Web (EBW), Bangkok, Thailand, 7-9 May 2013; pp. 274-279.

26. Available online: http:// epaper.ekantipur.com/kantipur/2016-02-16/1 (accessed on 2 March 2017).

27. Pokharel, M.; Park, J.S. Cloud computing: Future solution for e-governance. In Proceedings of the 3rd International Conference on Theory and Practice of Electronic Governance, Bogota, Colombia, 10-13 November 2009; pp. 409-410.

28. Bokhari, H. Realising hybrid model of eGovernment for citizen-centric eServices in developing countries. Analysis of eSahulat programme in Pakistan. In Proceedings of the IEEE 13th International Multitopic Conference, Islamabad, Pakistan, 14-15 December 2009; pp. 1-6. 